\title{
Uma análise do conteúdo de Botânica sob o enfoque Ciência-Tecnologia-Sociedade (CTS) em livros didáticos de Biologia do Ensino Médio
}

\author{
A botanical content analysis \\ under the Science-Technology-Society (STS) approach \\ in Biology high-school textbooks
}

Cássia Luã Pires de Souza ${ }^{1}$. https://orcid.org/0000-0002-1241-2219
Rosane Nunes Garcia ${ }^{2}$. https://orcid.org/0000-0002-4647-6245

Resumo: Este trabalho objetivou verificar os conteúdos de Botânica em livros didáticos de Biologia do Ensino Médio, analisando se o material segue o ensino sob o enfoque Ciência-Tecnologia-Sociedade (CTS). Pelo método da análise de conteúdo, categorias foram estabelecidas conforme documento avaliativo oficial dos livros e referencial teórico do ensino com enfoque CTS, para que excertos relacionados aos conteúdos inicial, principal, complementar e exercícios dos livros fossem classificados. Nesses livros didáticos, observou-se uma preocupação em adequar seu conteúdo a documentos oficiais e em apresentar aspectos relacionados ao ensino com enfoque CTS. Entretanto, o conteúdo principal ainda prioriza um ensino de caráter conceitual. É fundamental a reformulação na escrita desses livros, para que um ensino diferenciado, como é o ensino sob o enfoque CTS, voltado ao desenvolvimento da Alfabetização Científica dos estudantes, possa efetivamente contribuir para a formação de cidadãos críticos e atuantes na sociedade.

Palavras-chave: Livro didático. Ensino da botânica. Ensino médio. Ciência, tecnologia e sociedade. CTS.

\begin{abstract}
This work aimed to ascertain the botanical contents in Biology high-school textbooks, analyzing if they match the Science-Technology-Society (STS) approach. According to official evaluative documents and the STS theoretical referential approach, categories were stablished through content analysis. The initial, principal, and complementary contents, as well as the exercises were classified. There was concern with adapting the content in the books to official documents and showing aspects related to teaching under the STS approach. However, the main content in these books still prioritizes conceptual teaching. A written reformulation of these books is essential, especially in their main content, so that a differentiated teaching style, such as teaching under the STS approach, can effectively contribute to the formation of critical and active citizens in society, including the Scientific Literacy development of students.
\end{abstract}

Keywords: Textbooks. Botanical teaching. Secondary school. Science, technology and society. STS.

\footnotetext{
${ }^{1}$ Universidade Federal do Rio Grande do Sul (UFRGS), Instituto de Ciências Básicas da Saúde, Departamento de Bioquímica, Porto Alegre, RS, Brasil.

${ }^{2}$ UFRGS, Colégio Aplicação, Departamento de Ciências Exatas e da Natureza, Porto Alegre, RS, Brasil. E-mail: rosane.garcia@ufrgs.br
} 


\section{Introdução}

O Ensino da Botânica na sala de aula da Educação Básica confronta-se, muitas vezes, com dificuldades, como, por exemplo, a falta de importância dada pelo professor em relação ao estudo dos vegetais, e, até mesmo, a Botânica deixa de ser abordada na escola. A pouca interação entre homem-planta que Menezes et al. (2008) apontam também seria um fator que contribui para o desinteresse pelo estudo das plantas. Em relação a esse afastamento, “[...] isso pode ser explicado pelo fato de as plantas serem tão diferentes dos humanos quanto a adaptações e a comportamentos que se torna mais promissor para o professor ensinar sobre quem é mais próximo de nós, os outros animais, e sobre o próprio humano" (SOUZA; KINDEL, 2014, p. 54).

A Botânica defronta-se com seu ensino baseado, via de regra, na utilização do livro didático e na memorização excessiva de conteúdos, conceitos e termos (ROCKENBACH et al., 2012), logo, não tem feito referências à vida do aluno (FIGUEIREDO; COUTINHO; AMARAL, 2012) - embora isso não seja diferente do que acontece nas demais áreas do ensino de Ciências. Assim, pode-se dizer que, a Botânica passa a ser desconsiderada também pelos estudantes que, mais tarde, em sua formação, acabam apresentando incompreensões sobre a importância ecológica das plantas. O desconhecimento acerca dos motivos pelos quais os vegetais dominam os ecossistemas, diretamente relacionados às histórias de vida desses seres vivos, é um fato ainda visível na escola. Dessa maneira, propostas pedagógicas que podem permitir ao estudante refletir e tomar decisões acerca de questões que envolvem o seu cotidiano em conexão ao estudo dos vegetais é um constante desafio na Educação Básica brasileira. O trabalho com as temáticas de preservação das plantas no ambiente e o uso de tecnologias para produção de alimentos de origem vegetal em sala de aula - por exemplo - é uma maneira de contribuir para o exercício cidadania; devendo, portanto, ser motivado.

$\mathrm{Na}$ tentativa de se desvincular de situações que acometem o ensino e a aprendizagem da Botânica, como as apontadas anteriormente, é fundamental a contextualização desse ensino na vida do estudante, de modo que ele tenha condições de atuar de maneira crítica e consciente na sociedade. A contextualização, como modus docendi, significa englobar a articulação crítica das diferentes realidades como a social, a política, a cultural e a ambiental local ou mundial em que se insere o sujeito nas atividades escolares. Sendo assim, é necessária a transformação da abordagem pedagógica adotada pelo professor para ensinar Botânica. A adequação de seus recursos pedagógicos (principalmente, o livro didático) também é necessária, a fim de que essa mudança seja possibilitada. Para isso ocorrer, um caminho a seguir é o desenvolvimento de práticas educativas com enfoque Ciência-Tecnologia-Sociedade (CTS) na Educação Básica.

O propósito fundamental da abordagem CTS no Ensino de Ciências é clamar por uma educação científica mais humanista, em que, pela ação cidadã, as pessoas possam participar democraticamente do processo e da tomada de decisões de assuntos concernentes à ciência e à tecnologia na sociedade (ACEVEDO DÍAZ, 2004). Este autor aponta propostas educativas relacionadas ao movimento CTS, como a inclusão da dimensão social da Ciência e Tecnologia, o papel cultural e humanístico e o pensamento crítico em Ciência e Tecnologia, para que seja possível promover um ensino de Ciências com finalidades de aprendizagem mais amplas. 
Nos documentos oficiais do Ministério da Educação, tais como as Diretriz̨es curriculares nacionais gerais da educação básica (BRASIL, 2013), especialmente nas Diretrizes curriculares nacionais para o ensino médio (DCNEM), é defendido um currículo escolar voltado à cidadania (BRASIL, 2013). Segundo esse documento:

[...] no Ensino Médio há, portanto, condições para se criar uma educação cidadã, responsável, crítica e participativa, que possibilita a tomada de decisões transformadoras a partir do meio ambiente no qual as pessoas se inserem, em um processo educacional que supera a dissociação sociedade/ natureza. (BRASIL, 2013, p. 166).

As DCNEM utilizam como alicerces da proposta curricular do Ensino Médio o trabalho, a ciência, a tecnologia e a cultura de forma integrada, pois são campos que não se constituem isoladamente, dependendo da condição histórico-cultural da sociedade (BRASIL, 2013). Portanto, a partir das DCNEM, o currículo do Ensino Médio que se deseja alcançar no País não está longe do que se propõe no ensino com enfoque CTS.

Ainda se pode destacar que, em um meio social em que a Ciência e a Tecnologia se difundem de maneira contínua e persistente na vida das pessoas, essa concepção de ensino, isto é, a CTS, com propósitos dirigidos à Alfabetização Científica e ao exercício da cidadania, não apenas consideraria as vivências dos estudantes no desenvolvimento de propostas didáticas planejadas pelo professor como também daria maior atenção a seus interesses individuais e às necessidades coletivas (ACEVEDO DÍAZ, 2004).

Diante disso, é importante averiguar de que forma o ensino de ciências com enfoque CTS ocorre na Educação Básica, especialmente no Ensino Médio, no que se refere à Botânica. Para isso foram escolhidos, como materiais de análise, livros didáticos de Biologia do Ensino Médio incluídos no Guia de livros didáticos: PNLD 2015: ensino médio biologia (BRASIL, 2014). Os livros didáticos são, segundo Lajolo (1996), instrumentos que ainda influenciam fortemente a construção dos currículos escolares, sendo amplamente utilizados pelos professores e estudantes, além de definirem a qualidade de ensino brasileiro. À vista disso, justifica-se aqui a relevância de submetê-los à investigação. Além disso, o já referido Guia considera o livro didático “[...] mediador cultural e pedagógico que pode auxiliar para que a Biologia seja trabalhada pedagogicamente de modo que as discussões dessas temáticas contemporâneas estejam presentes nos currículos das escolas brasileiras" (BRASIL, 2014, p. 22), sinalizando, assim, mais uma confirmação de que é indispensável a realização de uma análise crítica de seu conteúdo, dado que há uma necessidade concreta de tornar o Ensino de Ciências mais significativo aos estudantes.

Este trabalho objetivou verificar se efetivamente os livros didáticos estão pautados em um ensino voltado para uma perspectiva diferenciada que não esteja exclusivamente canalizada pela promoção das aprendizagens de conceitos. Ou seja, pretendeu-se analisar se os conteúdos de Botânica de livros didáticos de Biologia do Ensino Médio do Brasil seguem o ensino sob o enfoque Ciência-Tecnologia-Sociedade (CTS). Levaram-se em conta, para isso, as indicações de documentos educacionais oficiais do Ministério da Educação (MEC) e as orientações de princípios CTS. 


\section{Metodologia}

A pesquisa desenvolvida neste trabalho é de abordagem qualitativa e quantitativa conduzida por meio da pesquisa documental, que, de acordo com Godoy (1995), utiliza diversos documentos (como livros) que não tenham sofrido tratamento analítico ou possam ser novamente analisados para a produção de dados e posteriores interpretações.

Foram escolhidos cinco volumes de livros didáticos de Biologia de Ensino Médio que contivessem o conteúdo de Botânica. Os livros selecionados e as partes analisadas estão relacionados no Quadro 1. Os principais assuntos tratados no material estavam relacionados à origem e evolução das plantas, à classificação e caracterização dos grandes grupos vegetais atuais e aos ciclos de vida desses grupos.

Esses volumes pertenciam a coleções de livros didáticos de Biologia reunidas no Guia de livros didáticos: PNLD 2015: ensino médio biologia (BRASIL, 2014), que as apresentava por meio de resenhas. Essas coleções incluídas no Programa Nacional do Livro Didático (PNLD) do ano de 2015 foram adquiridas pelo Fundo Nacional de Desenvolvimento da Educação (FNDE) e distribuídas a escolas públicas brasileiras que as escolheram. As escolas utilizam o acervo por um período de três anos, neste caso, 2015, 2016 e 2017.

Quadro 1 - Livros escolhidos para análise

\begin{tabular}{|c|c|c|c|}
\hline Identificação & $\begin{array}{l}\text { Autor / Ano } \\
\text { de publicação }\end{array}$ & Partes analisadas & $\begin{array}{c}\text { Páginas } \\
\text { analisadas }\end{array}$ \\
\hline Livro 1 (L1) & $\begin{array}{l}\text { Mendonça } \\
(2013)\end{array}$ & $\begin{array}{l}\text { Unidade 2: Diversidade biológica II: Plantas } \\
\text { Capítulo 6: Os grandes grupos de plantas }\end{array}$ & $86-113$ \\
\hline Livro 2 (L2) & $\begin{array}{l}\text { Bröckelmann } \\
\text { (2013) }\end{array}$ & $\begin{array}{l}\text { Unidade 2: Características e classificação das plantas } \\
\text { Temas: Reino Plantae; Células e os tecidos vegetais; } \\
\text { Principais partes das plantas; Classificação das } \\
\text { plantas; Reprodução em angiospermas }\end{array}$ & $56-91$ \\
\hline Livro 3 (L3) & $\begin{array}{l}\text { Silva, Sasson e } \\
\text { Caldini (2013) }\end{array}$ & $\begin{array}{l}\text { Unidade 4: O Reino Plantae } \\
\text { Capítulo 26: Os principais grupos de plantas }\end{array}$ & $\begin{array}{l}247-259 ; \\
316\end{array}$ \\
\hline Livro 4 (L4) & Osório (2013) & $\begin{array}{l}\text { Unidade 3: Plantas: seres multicelulares e } \\
\text { fotossintetizantes que nutrem seus alimentos } \\
\text { Capítulo 6: Grupos de plantas e seus ciclos de vida }\end{array}$ & $\begin{array}{l}72-93 ; \\
134-135\end{array}$ \\
\hline Livro 5 (L5) & $\begin{array}{l}\text { Amabis e } \\
\text { Martho (2013) }\end{array}$ & $\begin{array}{l}\text { Módulo 2: O reino das plantas } \\
\text { Capítulo 4: a diversidade das plantas }\end{array}$ & $70-89$ \\
\hline
\end{tabular}

Fonte: Elaborado pelas autoras.

Utilizou-se, como método de análise dos textos sobre o ensino da Botânica, a análise de conteúdo, que pode ser definida, de acordo com Bardin (2011, p. 48), como

[...] um conjunto de técnicas de análise das comunicações visando obter por procedimentos sistemáticos e objetivos de descrição do conteúdo das mensagens indicadores (quantitativos ou não) que permitam a inferência de conhecimentos relativos às condições de produção/recepção (variáveis inferidas) das mensagens. 
Para isso, foram estabelecidas - a priori - 17 categorias de análise, apontando o que se pretendia observar nos livros didáticos, a fim de classificar excertos do material de acordo com essas categorias (Quadro 2). Essas categorias foram baseadas em dois referenciais bibliográficos: o Guia de livros didáticos: PNLD 2015: ensino médio biologia (BRASIL, 2014) e o trabalho de Acevedo Díaz (2004). O referido Guia é orientado por vários critérios avaliativos, os quais se atentam à realidade da Educação Básica brasileira e aos desafios do Ensino Médio atual (BRASIL, 2014). Dentre esses critérios, podem-se destacar: o respeito à legislação brasileira vigente (Constituição da República Federativa do Brasil, a Lei de Diretrizes e Bases da Educação Nacional e Diretrizes Curriculares Nacionais para o Ensino Médio); a correção, contextualização e atualização de conceitos, princípios, informações e procedimentos nos textos e nas atividades propostas (como é o caso do estímulo à participação do educando em debates contemporâneos, que incluem temáticas da Biologia com outras áreas do conhecimento); a construção da cidadania e convivência em sociedade (se o material é isento de estereótipos e preconceitos de origem e gênero, por exemplo) (BRASIL, 2014). Dessa maneira, considerou-se esse Guia um elemento pedagógico bastante rico e, portanto, foi importante sua utilização neste artigo. Ou seja, alguns de seus critérios avaliativos serviram de base para a criação de categorias de análise do conteúdo de Botânica dos livros didáticos apresentados no Quadro 1. Desse modo, as categorias I até VIII, que estão agrupadas na classificação PNLD/2015: Biologia (conforme Quadro 2), foram norteadas por esse Guia, o qual ainda aponta que "[...] na sociedade contemporânea a exigência é cada vez maior para que a escola tenha sensibilidade e atenção para as profundas e rápidas mudanças com que os jovens se defrontam no campo, da cultura da ciência da tecnologia, das artes, do trabalho" (BRASIL, 2014, p. 8). Isso demonstra que o livro didático, como instrumento de apoio pedagógico às aulas, precisa fazer sentido na aprendizagem e na formação crítica do estudante. Por essa razão, o livro didático merece ser analisado. Em se tratando de enfoque CTS, o referencial teórico Acevedo Díaz (2004) foi considerado fundamental para verificar a ocorrência dessa perspectiva de ensino no conteúdo dos livros, pois este autor traz propostas pedagógicas que proporcionam objetivos mais amplos para o Ensino de Ciências, quando se aborda a ênfase CTS na Educação. Dessa forma, as categorias IX até XVI foram agrupadas na classificação CTS (Quadro 2) e relacionadas às propostas educativas para promover o movimento CTS no Ensino de Ciências desenvolvidas por esse mesmo autor. A última categoria (XVII) foi classificada como PNLD/2015: Biologia e CTS por se considerar que ela está relacionada aos dois referenciais utilizados para a análise (Quadro 2).

Para verificar a ocorrência das categorias no conteúdo de Botânica de cada livro didático, os tipos de textos foram divididos da seguinte maneira:

a) Conteúdo inicial (CI): material inicial (como textos introdutórios e questionamentos);

b) Conteúdo principal (CP): material principal (como o corpo dos textos descrevendo os conceitos e conteúdos);

c) Conteúdo complementar (CC): material complementar, como textos suplementares, questionamentos e propostas de projetos interdisciplinares;

d) Exercícios (EX): atividades apresentadas nas partes analisadas dos livros.

No que se refere ao conteúdo dos textos, foi feita a análise por parágrafos. Cada questionamento foi analisado individualmente. Da mesma maneira, foi avaliado cada exercício, embora este pudesse apresentar mais de uma questão, o que acabaria formando um conjunto 
de um único exercício. Assim, para um mesmo parágrafo de texto, questionamento ou exercício, mais de uma categoria poderia estar presente. Os projetos foram categorizados por apresentarem propostas pedagógicas interessantes relacionadas, principalmente, à perspectiva CTS. Entretanto, foram analisados à parte, já que não estão presentes em todos os livros investigados.

Quadro 2 - Categorias estabelecidas para análise do conteúdo de Botânica nos livros didáticos

\begin{tabular}{|c|c|c|}
\hline \multicolumn{3}{|c|}{$\begin{array}{ll}\text { Categorias } \\
\end{array}$} \\
\hline \multirow[t]{8}{*}{$\begin{array}{l}\text { PNLD/2015: } \\
\text { Biologia }\end{array}$} & I & $\begin{array}{l}\text { A Botânica no cotidiano: mostra a participação das plantas no cotidiano do } \\
\text { estudante? Ex.: na alimentação }\end{array}$ \\
\hline & II & $\begin{array}{l}\text { Respeito às formas de vida: estimula o respeito a diferentes formas de vida, } \\
\text { especialmente o respeito às plantas? }\end{array}$ \\
\hline & III & $\begin{array}{l}\text { Conhecimentos populares: conhecimentos populares, étnicos e culturais } \\
\text { relacionados à Botânica estão presentes? }\end{array}$ \\
\hline & IV & $\begin{array}{l}\text { Caráter interdisciplinar: possui caráter interdisciplinar (relaciona a Botânica } \\
\text { com outras áreas de conhecimento)? }\end{array}$ \\
\hline & $\mathrm{V}$ & $\begin{array}{l}\text { Superação da visão a-histórica: supera a visão a-histórica do conhecimento } \\
\text { botânico (os conhecimentos científicos relacionados à Botânica estão } \\
\text { envolvidos por contextos histórico, social, cultural, tecnológico)? }\end{array}$ \\
\hline & VI & $\begin{array}{l}\text { História evolutiva: considera a história evolutiva das plantas para apresentá- } \\
\text { las ao estudante? }\end{array}$ \\
\hline & VII & $\begin{array}{l}\text { Espírito cooperativo: estimula o trabalho em grupo, a fim de desenvolver o } \\
\text { espírito cooperativo no estudante? }\end{array}$ \\
\hline & VIII & $\begin{array}{l}\text { Espírito investigativo: estimula o trabalho individual e/ou em grupo, a fim } \\
\text { de desenvolver o espírito investigativo no estudante, sobretudo em atividades } \\
\text { dentro da comunidade escolar? }\end{array}$ \\
\hline \multirow[t]{8}{*}{ CTS } & IX & $\begin{array}{l}\text { Conceitos em destaque: os conceitos destacados estão relacionados ao } \\
\text { ensino CTS? }\end{array}$ \\
\hline & $\mathrm{X}$ & $\begin{array}{l}\text { Ciência e tecnologia: inclui contribuições da ciência e tecnologia para a } \\
\text { Botânica e sociedade? }\end{array}$ \\
\hline & $\mathrm{XI}$ & $\begin{array}{l}\text { Dimensão política: apresenta questões políticas (locais e globais) } \\
\text { relacionadas à Botânica? Ex.: legislação }\end{array}$ \\
\hline & XII & $\begin{array}{l}\text { Dimensão social: apresenta questões sociais (locais e globais) relacionadas à } \\
\text { Botânica? }\end{array}$ \\
\hline & XIII & $\begin{array}{l}\text { Dimensão ambiental: apresenta questões ambientais (locais e globais) } \\
\text { relacionadas a Botânica? }\end{array}$ \\
\hline & XIV & $\begin{array}{l}\text { Dimensão cultural: apresenta questões culturais (locais e globais) } \\
\text { envolvendo Botânica? }\end{array}$ \\
\hline & $\mathrm{XV}$ & $\begin{array}{l}\text { Ética e valores da ciência e tecnologia: considera a ética e os valores da } \\
\text { ciência e tecnologia ao abordar Botânica? }\end{array}$ \\
\hline & XVI & $\begin{array}{l}\text { Pensamento crítico: estimula a formação do pensamento crítico, } \\
\text { incentivando debates em torno das relações entre a ciência, a tecnologia e a } \\
\text { sociedade? }\end{array}$ \\
\hline $\begin{array}{l}\text { PNLD/2015: } \\
\text { Biologia e } \\
\text { CTS }\end{array}$ & XVII & $\begin{array}{l}\text { Formação de opiniões: estimula a formação de opiniões, tomada de } \\
\text { decisões e resolução de problemas e/ou de questões cotidianas que envolvam } \\
\text { CTS, como forma do aluno expressar/desenvolver sua cidadania? }\end{array}$ \\
\hline
\end{tabular}

Fonte: Elaborado pelas autoras. 


\section{Resultados e discussões}

De modo geral, foi possível observar que os autores dos livros didáticos analisados se preocuparam em adequar o conteúdo de Botânica desses materiais a documentos educacionais oficiais brasileiros. Notou-se que os materiais, além disso, apresentavam em alguns trechos aspectos relacionados ao ensino sob o enfoque CTS, quando tratavam da Botânica. Entretanto, foi no L2 que os excertos retirados puderam ser classificados em maior diversidade de categorias e este também se destacou em relação ao que se buscou encontrar nos livros.

\section{Exemplificando como foram classificados os textos dos livros didáticos em Projetos}

Pode-se destacar que os projetos apresentados nos livros didáticos L2, L3 e L4 se caracterizam por apresentar atividades que se relacionam a temáticas ambientais e atuais que envolvem as plantas no cotidiano do estudante, de modo que também se reconheça a importância delas à manutenção da vida. Nos textos desses livros didáticos, há interação entre os conteúdos abordados de Botânica (ou de Biologia) com outras áreas do conhecimento como a Matemática, a Química, a Geografia e as Artes. Além disso, tais atividades são propostas (sempre por meio de roteiro de elaboração) para serem desenvolvidas em grupos e também por meio de atividades de investigação, como livros e páginas da Internet ou, até mesmo, entrevistas na comunidade em que vivem, estimulando, entre outras características, a cooperação, o espírito investigativo e a criatividade no estudante. Outro aspecto importante desses projetos é o incentivo ao debate em seu processo de elaboração, a formação de opiniões e a busca por soluções de problemas sociais e ambientais locais, ao se fazer relações entre ciência, tecnologia e sociedade. Portanto, esses projetos (descritos a seguir) encontrados nos livros L2, L3 e L4 foram classificados nas categorias I, II, IV, VII, VIII, X, XII, XIII, XVI e XVII.

No projeto Reaproveitamento de resíduos sólidos, no L2, "a turma desenvolverá um projeto de reutilização de resíduos sólidos produzidos em sua região” (BRÖCKELMANN, 2013, p. 90). Para seu desenvolvimento, que ocorreria ao longo do ano letivo, estava incluída a escolha de um local para realizar o projeto, uma tecnologia para reaproveitamento dos resíduos, a avaliação das dificuldades para desenvolvê-lo, uma estimativa do ganho financeiro com a reutilização do material, a apresentação do projeto e a divulgação de qual tipo de reutilização seria viável para sua cidade (BRÖCKELMANN, 2013).

O projeto presente no L3 denominado Biodiversidade das plantas propõe atividades que buscam a "[...] compreensão da importância de um fator químico para o desenvolvimento dos vegetais, para a análise da importância e as consequências da agricultura moderna" (SILVA; SASSON; CALDINI, 2013, p. 316). Entre as atividades, podem-se citar a pesquisa de $\mathrm{pH}$ ideal para o desenvolvimento da maioria das plantas, a escrita de textos mostrando a relação entre aumento da população humana e a biodiversidade e a discussão das vantagens e desvantagens da monocultura para a agroenergia (SILVA; SASSON; CALDINI, 2013).

Por fim, no L4, o projeto Os seres vivos no teatro: entendendo as relações entre os organismos de vários reinos propõe que os alunos em equipes criem uma pequena peça ou cena a partir de um trecho de texto a ser apresentada à comunidade escolar. Em suma, cada equipe escolhe um dos grupos estudados, como, por exemplo, os vírus, os fungos e plantas, procurando informações 
sobre como espécies do grupo interagem com a natureza ou com os humanos para, assim, elaborarem a peça. Também é recomendado que sejam criados cartazes de divulgação das peças. Ao final, após a apresentação do espetáculo, sugere-se uma discussão, a fim de verificar se os temas das peças foram abordados claramente, se o público manifestou interesse pela atividade e quais foram as contribuições do projeto à comunidade (OSORIO, 2013).

\section{Apresentando os dados produzidos e as análises}

Nos livros didáticos investigados, percebe-se que existe uma preocupação na adequação dos textos referente ao que se propõe em documentos oficiais do MEC, já que a maioria dos trechos encontrados (L1, L3 e L5) foram classificados nas categorias do PNLD 2015: Biologia (Figura 1).

Figura 1 - PNLD 2015: biologia: indica o número total de ocorrências das categorias I a VIII nos conteúdos inicial, principal e complementar e nos exercícios nos cinco livros analisados

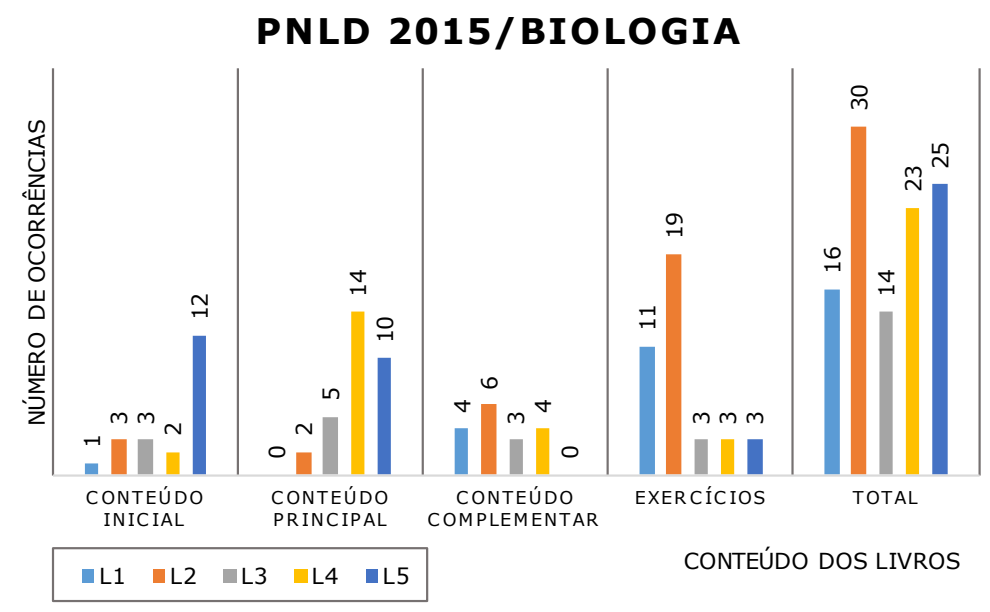

L1 (Livro 1); L2 (Livro 2); L3 (Livro 3); L4 (Livro 4); L5 (Livro 5).

Fonte: Elaborada pelas autoras.

Além disso, verificou-se que o material possui aspectos relacionados ao ensino com enfoque CTS (Figura 2), os quais precisam ser levados em conta nos currículos da Educação Básica e, em consequência, na aprendizagem dos estudantes. No entanto, como afirma Kindel (2008, p. 92), “[...] por mais bem escrito, fundamentado e bem ilustrado que um livro didático seja, jamais dará conta das múltiplas linguagens e explicações da Ciência”. Ou seja, apesar de os livros didáticos analisados terem textos diferenciados (Quadro 3), isso ainda é ínfimo diante da ênfase conceitual apresentada no constituinte maior desses livros - o seu conteúdo principal. Isso significa que, na exposição das temáticas de Botânica neste conteúdo, valoriza-se uma quantidade excessiva de termos (os quais estão quase sempre em destaque), de conceitos e definições 
que se configuram, dessa maneira, como fundamentais não só à explicação e à compreensão de processos e de fenômenos relacionados às plantas, como também à apresentação de sistemas de classificação adotados aos grandes grupos vegetais. Em consequência disso, a maioria dos exercícios propostos nesses livros tendem a privilegiar a memorização do assunto/conceitos tratados. Para Kindel (2008, p. 92), “[...] exercícios de fixação descontextualizados aumentam a distância entre os conhecimentos biológicos - de que o sujeito precisa para compreender a vida em todas as suas manifestações - e a realidade do/as alunos/as".

Dessa maneira, defende-se aqui um Ensino de Ciências sob o enfoque CTS. Entretanto, deve-se ter em vista que essa concepção de ensino vem a exigir dos docentes uma desvinculação da abordagem tradicional de ensino, baseada na memorização superficial de conceitos e definições de conteúdos trabalhados em sala de aula. Estes, quando selecionados para a construção de currículos, na maioria das vezes, são explorados a partir do que se apresenta no conteúdo principal dos livros didáticos. Segundo Bispo Filho et al. (2013), um dos propósitos de um currículo sob o enfoque CTS está ligado ao entendimento do estudante de que ele se encontra imerso em uma realidade social, a qual exerce influência direta em sua vida, e que as relações entre Ciência e Tecnologia possam ser apresentadas. Esses autores afirmam que

[...] um dos objetivos de um currículo CTS é facilitar a compreensão dos estudantes em relação às experiências relacionadas com os fenômenos que os cercam em suas vidas diárias, de tal forma que a ciência escolar aproxime o saber tecnológico da vida social, no qual o objetivo passa a ser preencher o vazio causado pelo currículo tradicional de Ciências [...]. (BISPO FILHO et al., 2013, p. 316).

Figura 2. CTS: indica o número total de ocorrências das categorias IX a XVI nos conteúdos inicial, principal e complementar e nos exercícios nos cinco livros analisados

\section{CTS}

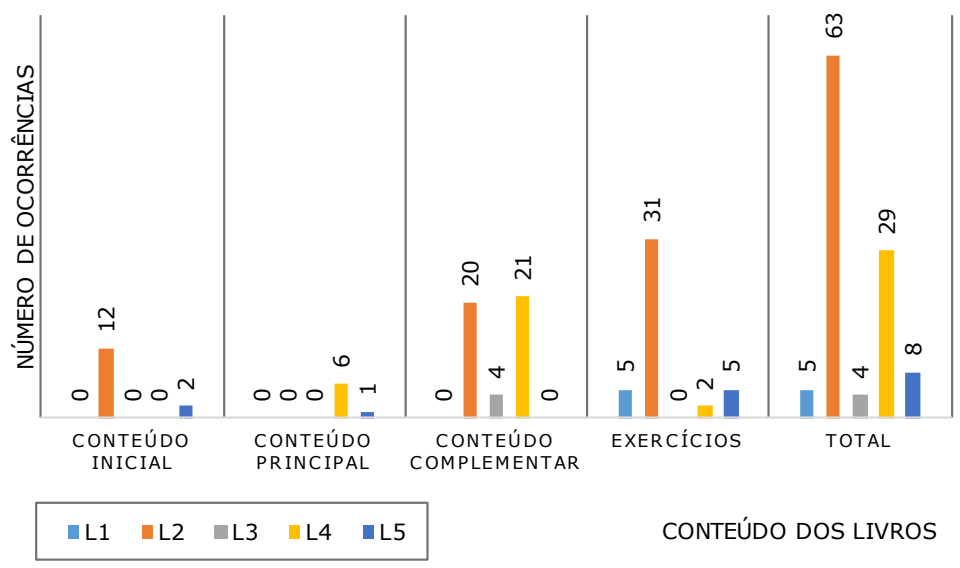

L1 (Livro 1); L2 (Livro 2); L3 (Livro 3); L4 (Livro 4); L5 (Livro 5).

Fonte: Elaborada pelas autoras. 
No que se refere aos sistemas de classificação das plantas, os livros seguem a história evolutiva desses seres vivos, e suas características adaptativas sobressaem no conteúdo principal desses livros. Observa-se na tabela 1 que é priorizada a história evolutiva e ocorre mais vezes no CC no conteúdo de Botânica do livro 1, embora em EX ocorra a predominância dos excertos. Já no L3, história evolutiva destaca-se e aparece mais vezes em CP, embora a maior ocorrência de categorias esteja em CC (tabela 2). O mesmo ocorre no L5 em que aquela categoria predomina no CP, embora a maior ocorrência de categorias se encontra em CI (tabela 3). Por outro lado, foi possível verificar que a relação da Botânica com o dia a dia do estudante ocorre no conteúdo dos livros. A Botânica no cotidiano é destaque no CC no L4; os projetos propostos nos livros didáticos 2, 3 e 4 e os exemplos 1, 3 e 9 dos excertos (Quadro 3) também tiveram essa classificação. Entretanto, no conteúdo principal, especialmente, tal relação aparece como forma de utilidade/benefício para o ser humano (por exemplo, na indústria farmacêutica e alimentícia), dando a impressão de que as plantas importam somente para a exploração quando se necessita e desenvolvendo uma ideia de ciência e tecnologia como um avanço para melhorar a vida. Essa é uma característica da visão tecnocrática da Ciência e da Tecnologia alicerçada no modelo linear de progresso, estabelecendo uma neutralidade da Ciência e da Tecnologia (AULER, 2007; AULER; BAZZO, 2001; CAMPOS, 2010). Para Campos (2010, p. 26): “[...] este modelo indica que o desenvolvimento social é uma consequência de desenvolvimento científico. Este promoveria o desenvolvimento tecnológico, que propiciaria o desenvolvimento econômico, o qual, finalmente, permitiria o desenvolvimento social".

Entende-se, portanto, que essa percepção estanque e irredutível da Ciência e da Tecnologia que se configura ainda nos livros didáticos precisa ser subjugada, pois, de acordo com Auler (2007), as concepções históricas de superioridade/neutralidade da ciência (a qual elimina o sujeito do processo científico e tecnológico), da perspectiva salvacionista da ciência e tecnologia (visão de que só a ciência é capaz de resolver as mazelas do mundo e salvar a sociedade) e do determinismo tecnológico (a tecnologia é autossuficiente e determina as mudanças sociais) precisam ser superadas, contribuindo, assim, para que o sujeito consiga realizar uma leitura crítica do mundo e possa participar ativamente na sociedade. Dessa maneira, "[...] a superação de uma percepção ingênua e mágica da realidade exige, cada vez mais, uma compreensão dos sutis e delicados processos de interação entre CTS" (AULER, 2007, p. 178).

Quadro 3 - Exemplos de excertos (trechos e/ou paráfrases) do material analisado com sua devida classificação em categorias

\begin{tabular}{|l|l|l|l|}
\hline Livros & $\begin{array}{c}\text { Tipos } \\
\text { de } \\
\text { texto }\end{array}$ & \multicolumn{1}{|c|}{ Excertos } & $\begin{array}{c}\text { Classificação } \\
\text { dos excertos } \\
\text { (Categorias) }\end{array}$ \\
\hline 1 & CI & $\begin{array}{l}\text { 1. "O que você conhece sobre plantas? Certamente você observa } \\
\text { e convive com muitas delas, em vasos que enfeitam a sua } \\
\text { casa, em um prato de salada, no caminho até sua escola [...]" } \\
\text { (MENDONÇA, 2013, p. 86). }\end{array}$ & I \\
\hline
\end{tabular}

continua 
Quadro 3 - continuação

\begin{tabular}{|c|c|c|c|}
\hline Livros & $\begin{array}{l}\text { Tipos } \\
\text { de } \\
\text { texto }\end{array}$ & Excertos & $\begin{array}{l}\text { Classificação } \\
\text { dos excertos } \\
\text { (Categorias) }\end{array}$ \\
\hline 1 & $\mathrm{EX}$ & $\begin{array}{l}\text { 2. Exercício } 13 \text { (p. 112) - narra brevemente quem foi Wangari } \\
\text { Maathai, bióloga que atuou em defesa dos direitos da mulher e } \\
\text { criou um movimento, aliando ambientalismo e direitos humanos; } \\
\text { a partir disso, propõe-se que os alunos procurem saber a respeito } \\
\text { de projetos socioambientais existentes no local em que vivem, } \\
\text { que entrevistem os envolvidos e que divulguem essas ações } \\
\text { (MENDONÇA, 2013, p. 112). }\end{array}$ & $\begin{array}{l}\text { II, IV, VIII, } \\
\text { XII e XIII }\end{array}$ \\
\hline 2 & CC & $\begin{array}{l}\text { 3. Complemento Plantas na África e no Brasil: "Diversas plantas } \\
\text { foram trazidas da África para o Brasil, e em muitos casos o } \\
\text { conhecimento tradicional atrelado a elas também foi incorporado } \\
\text { à nossa cultura. Um exemplo é a babosa ou aloé (Aloe vera). [...]" } \\
\text { (BRÖCKELMANN, 2013, p. 70). }\end{array}$ & I, III e XIV \\
\hline 1 & EX & $\begin{array}{l}\text { 4. Exercício } 12 \text { (p. 112) - aponta-se o uso de briófitas como } \\
\text { indicadoras de qualidade ambiental; indaga-se o estudante sobre } \\
\text { a existência de outras formas de utilização das plantas para } \\
\text { combater a degradação ambiental, propondo que seja discutido } \\
\text { o assunto com os colegas e, caso necessite, busque informações } \\
\text { sobre o tema (MENDONÇA, 2013, p. 112). }\end{array}$ & $\begin{array}{l}\text { IV, VIII, X, } \\
\text { XIII e XVI }\end{array}$ \\
\hline 2 & CI & $\begin{array}{l}\text { 5. Questionamento da página } 57 \text { - são mostrados dados de } \\
\text { espécies da flora brasileira catalogadas na obra Flora Brasiliensis } \\
\text { (1868) e também das reconhecidas até 2012, propondo } \\
\text { aos estudantes que discutam e comparem esses números, } \\
\text { considerando o contexto histórico e tecnológico da época em } \\
\text { que ocorreu a expedição de Martius (que resultou na publicação } \\
\text { daquela obra) com as atuais (BRÖCKELMANN, 2013). }\end{array}$ & V, X e XVI \\
\hline 5 & $\mathrm{CP}$ & $\begin{array}{l}\text { 6. "Uma estratégia evolutiva importante desenvolvida pelas } \\
\text { plantas, que possibilitou sua independência da água líquida } \\
\text { para a fecundação, constituiu em mudança radical no ciclo de } \\
\text { vida alternante herdado das algas ancestrais [...]" (AMABIS; } \\
\text { MARTHO, 2013, p. } 75 \text { ). }\end{array}$ & VI \\
\hline 2 & EX & $\begin{array}{l}\text { 7. Exercício na página } 87 \text { - solicita-se ao estudante que pesquise } \\
\text { a função das matas ciliares para os rios, discuta com os colegas } \\
\text { sobre a importância de preservar essas matas. Indaga-se também } \\
\text { sobre as consequências do desmatamento das matas ciliares, } \\
\text { sobre a existência dessas áreas no local em que vivem, sobre a } \\
\text { importância de se ter um Código Florestal, além de sugerir que se } \\
\text { pesquise a respeito de como o Código é elaborado e que o aluno } \\
\text { opine acerca disso (BRÖCKELMANN, 2013). }\end{array}$ & $\begin{array}{l}\text { VIII, XI, XIII, } \\
\text { XVI e XVII }\end{array}$ \\
\hline
\end{tabular}


Quadro 3 - continuação

\begin{tabular}{|l|l|l|c|}
\hline Livros & $\begin{array}{c}\text { Tipos } \\
\text { de } \\
\text { texto }\end{array}$ & \multicolumn{1}{|c|}{ Excertos } & $\begin{array}{c}\text { Classificação } \\
\text { dos excertos } \\
\text { (Categorias) }\end{array}$ \\
\hline 3 & CC & $\begin{array}{l}\text { 8. Complemento "Xaxim" (p. 251) - é proposto que os } \\
\text { estudantes realizem uma pesquisa a respeito de Dicksonia } \\
\text { sellewiana, planta de onde se extrai o xaxim, além das } \\
\text { consequências de sua extração e de quais plantas poderiam } \\
\text { substituíla. Sugere-se, além disso, que os alunos formem uma } \\
\text { associação de preservação ambiental junto com a comunidade } \\
\text { escolar, a fim de recuperar áreas verdes do seu município, fazendo } \\
\text { o plantio de plantas nativas (SILVA; SASSON; CALDINI, 2013). }\end{array}$ & $\begin{array}{l}\text { VII, VIII, XII, } \\
\text { XIII e XVII }\end{array}$ \\
\hline 4 & EX & $\begin{array}{l}\text { 9. Exercício 15 (p. 93) - trata do potencial farmacológico das } \\
\text { plantas medicinais brasileiras, em que se afirma que cerca de } \\
\text { um décimo das angiospermas do mundo ocorrem no Brasil. É } \\
\text { proposto que o estudante comente a respeito disso, considerando } \\
\text { o tamanho do território e as condições climáticas do Brasil. } \\
\text { Precisa, também, opinar acerca de como o efeito da destruição de } \\
\text { matas nativas atuaria sobre a descoberta de plantas com potencial } \\
\text { farmacológico, além de criar uma lista de plantas medicinais e } \\
\text { suas utilizações, podendo buscar essas informações, realizando } \\
\text { entrevistas (OSORIO, 2013). }\end{array}$ & XIII e XVII \\
\hline
\end{tabular}

Fonte: Elaborado pelas autoras.

Partes que se caracterizam por versar sobre a contextualização da Botânica na vida dos estudantes e pela contribuição na formação de cidadãos atuantes na sociedade - um ensino com enfoque CTS - são deixadas praticamente de fora do conteúdo principal dos livros, isto é, ficam restritas ao conteúdo inicial, complementar e exercícios (conforme os dados observados nos L2 e L4). Na análise do L2 (tabela 4), os dados indicam que a predominância de trechos ocorre em EX.

Tabela 1 - Ocorrência das categorias no conteúdo do L1

\begin{tabular}{cllccccc}
\hline & \multicolumn{1}{c}{ Categorias } & CI & CP & CC & EX & Total \\
\hline PNLD 2015/ & I & A Botânica no cotidiano & 1 & 0 & 0 & 0 & 1 \\
Biologia & II & Respeito às formas de vida & 0 & 0 & 0 & 1 & 1 \\
& III & Conhecimentos populares & 0 & 0 & 0 & 0 & 0 \\
& IV & Caráter interdisciplinar & 0 & 0 & 0 & 5 & 5 \\
& V & Superação da visão a-histórica & 0 & 0 & 0 & 0 & 0 \\
& VI & História evolutiva & 0 & 0 & 4 & 3 & 7 \\
& VII & Espírito cooperativo & 0 & 0 & 0 & 0 & 0 \\
& VIII & Espírito investigativo & 0 & 0 & 0 & 2 & 2 \\
\hline
\end{tabular}


Tabela 1 - continuação

\begin{tabular}{|c|c|c|c|c|c|c|c|c|}
\hline \multicolumn{4}{|c|}{ Categorias } & CI & CP & CC & EX & Total \\
\hline \multirow[t]{7}{*}{ CTS } & IX & Conceitos em destaque & & 0 & 0 & 0 & 0 & 0 \\
\hline & $\mathrm{X}$ & Ciência e tecnologia & & 0 & 0 & 0 & 1 & 1 \\
\hline & XI & Dimensão política & & 0 & 0 & 0 & 0 & 0 \\
\hline & XII & Dimensão social & & 0 & 0 & 0 & 1 & 1 \\
\hline & XIII & Dimensão ambiental & & 0 & 0 & 0 & 2 & 2 \\
\hline & XIV & Dimensão cultural & & 0 & 0 & 0 & 0 & 0 \\
\hline & XV & $\begin{array}{l}\text { Ética e valores da ciência e } \\
\text { tecnologia }\end{array}$ & & 0 & 0 & 0 & 0 & 0 \\
\hline \multirow{3}{*}{ PNLD e CTS } & XVI & Pensamento crítico & & 0 & 0 & 0 & 1 & 1 \\
\hline & XVII & Formação de opiniões & & 0 & 0 & 0 & 0 & 0 \\
\hline & & & Total & 1 & 0 & 4 & 16 & 21 \\
\hline
\end{tabular}

Fonte: Elaborada pelas autoras.

Tabela 2 - Ocorrência das categorias no conteúdo do L3

\begin{tabular}{cllccccc}
\hline & \multicolumn{2}{c}{ Categorias } & CI & CP & CC & EX & Total \\
\hline PNLD 2015/ & I & A Botânica no cotidiano & 1 & 0 & 1 & 0 & 2 \\
Biologia & II & Respeito às formas de vida & 0 & 0 & 0 & 0 & 0 \\
& III & Conhecimentos populares & 0 & 0 & 0 & 0 & 0 \\
& IV & Caráter interdisciplinar & 0 & 0 & 0 & 0 & 0 \\
& V & Superação da visão a-histórica & 0 & 0 & 0 & 0 & 0 \\
& VI & História evolutiva & 2 & 5 & 0 & 3 & 10 \\
& VII & Espírito cooperativo & 0 & 0 & 1 & 0 & 1 \\
& VIII & Espírito investigativo & 0 & 0 & 1 & 0 & 1 \\
& IX & Conceitos em destaque & 0 & 0 & 0 & 0 & 0 \\
& X & Ciência e tecnologia & 0 & 0 & 0 & 0 & 0 \\
& XI & Dimensão política & 0 & 0 & 0 & 0 & 0 \\
& XII & Dimensão social & 0 & 0 & 1 & 0 & 1 \\
& XIII & Dimensão ambiental & 0 & 0 & 3 & 0 & 3 \\
& XIV & Dimensão cultural & 0 & 0 & 0 & 0 & 0 \\
& XV & Ética e valores da ciência e tecnologia & 0 & 0 & 0 & 0 & 0 \\
& XVI & Pensamento crítico & 0 & 0 & 0 & 0 & 0 \\
& XVII & Formação de opiniões & 0 & 0 & 1 & 0 & 1 \\
& & & 3 & 5 & 8 & 3 & 19 \\
\hline
\end{tabular}

Fonte: Elaborada pelas autoras.

Outra característica importante que se nota em algumas partes dos livros é o caráter interdisciplinar observado nos projetos propostos nos livros 2, 3 e 4 e nos excertos 2 e 9 (Quadro 3). Tais exemplos extrapolam conteúdos da Biologia (em especial, a Botânica), permitindo que os estudantes utilizem conhecimentos de outras áreas e abram discussões em grupos para 
desenvolver tais atividades, contribuindo para a formação de opiniões. De acordo com Krasilchik e Marandino (2007, p. 8), "[...] o ensino de Ciências passou de uma fase de apresentação da ciência como neutra para uma visão interdisciplinar, em que o contexto da pesquisa científica e suas consequências sociais, políticas e culturais são elementos marcantes". A interdisciplinaridade colaboraria aqui como uma forma de ultrapassar a neutralidade da ciência e da tecnologia encontrada nos livros e também como forma de contextualizar a Botânica na vida do estudante, permitindo, portanto, que relações CTS existam. Entretanto, embora a interdisciplinaridade admita a quebra de barreira entre as áreas de conhecimento, possibilitando que temáticas mais amplas (além dos conteúdos botânicos explorados nos livros didáticos) possam ser concebidas e entrelaçadas no ensino de Ciências, esse caráter ainda é pouco aceito pelos docentes. Para Krasilchik e Marandino (2007), os professores apresentam dúvidas acerca do que a interdisciplinaridade demanda e também acreditam que possa haver perda de rigor dos conteúdos que devam trabalhar, assim acabam mantendo aulas tradicionais que são cômodas e seguras, visto que não irão favorecer, no meio escolar, reflexões e discussões, as quais exigem a exposição de valores individuais e coletivos e de diferentes pontos de vista que ultrapassam a sala de aula.

Tabela 3 - Ocorrência das categorias no conteúdo do L5

\begin{tabular}{cclccccc}
\hline & \multicolumn{2}{c}{ Categorias } & CI & CP & CC & EX & Total \\
\hline PNLD 2015/ & I & A Botânica no cotidiano & 7 & 0 & 0 & 0 & 7 \\
Biologia & II & Respeito às formas de vida & 3 & 0 & 0 & 0 & 3 \\
& III & Conhecimentos populares & 0 & 0 & 0 & 0 & 0 \\
& IV & Caráter interdisciplinar & 0 & 0 & 0 & 0 & 0 \\
& V & Superação da visão a-histórica & 0 & 0 & 0 & 0 & 0 \\
& VI & História evolutiva & 2 & 10 & 0 & 3 & 15 \\
& VII & Espírito cooperativo & 0 & 0 & 0 & 0 & 0 \\
& VIII & Espírito investigativo & 0 & 0 & 0 & 0 & 0 \\
& IX & Conceitos em destaque & 0 & 0 & 0 & 0 & 0 \\
& X & Ciência e tecnologia & 1 & 0 & 0 & 2 & 3 \\
& XI & Dimensão política & 0 & 0 & 0 & 1 & 1 \\
& XII & Dimensão social & 0 & 0 & 0 & 1 & 1 \\
& XIII & Dimensão ambiental & 1 & 1 & 0 & 1 & 3 \\
& XIV & Dimensão cultural & 0 & 0 & 0 & 0 & 0 \\
& XV & Ética e valores da ciência e tecnologia & 0 & 0 & 0 & 0 & 0 \\
& XVI & Pensamento crítico & 0 & 0 & 0 & 0 & 0 \\
PNLD e CTS & XVII & Formação de opiniões & 0 & 0 & 0 & 1 & 1 \\
& & & 14 & 11 & 0 & 9 & 34 \\
\hline
\end{tabular}

Fonte: Elaborada pelas autoras. 
Tabela 4. Ocorrência das categorias no conteúdo do L2

\begin{tabular}{cclccccc}
\hline & \multicolumn{2}{c}{ Categorias } & CI & CP & CC & EX & Total \\
\hline PNLD 2015/ & I & A Botânica no cotidiano & 0 & 0 & 3 & 2 & 5 \\
Biologia & II & Respeito às formas de vida & 1 & 0 & 0 & 1 & 2 \\
& III & Conhecimentos populares & 0 & 0 & 2 & 0 & 2 \\
& IV & Caráter interdisciplinar & 1 & 0 & 1 & 8 & 10 \\
& V & Superação da visão a-histórica & 1 & 0 & 0 & 1 & 2 \\
& VI & História evolutiva & 0 & 2 & 0 & 1 & 3 \\
& VII & Espírito cooperativo & 0 & 0 & 0 & 1 & 1 \\
& VIII & Espírito investigativo & 0 & 0 & 0 & 5 & 5 \\
& IX & Conceitos em destaque & 0 & 0 & 0 & 0 & 0 \\
& X & Ciência e tecnologia & 1 & 0 & 8 & 7 & 16 \\
& XI & Dimensão política & 0 & 0 & 0 & 2 & 2 \\
& XII & Dimensão social & 1 & 0 & 0 & 7 & 8 \\
& XIII & Dimensão ambiental & 8 & 0 & 7 & 9 & 24 \\
& XIV & Dimensão cultural & 0 & 0 & 2 & 1 & 3 \\
& XV & Ética e valores da ciência e tecnologia & 0 & 0 & 0 & 0 & 0 \\
& XVI & Pensamento crítico & 2 & 0 & 3 & 5 & 10 \\
& XVII & Formação de opiniões & 1 & 0 & 0 & 5 & 6 \\
& & & 16 & 2 & 26 & 55 & 99 \\
\hline
\end{tabular}

Fonte: Elaborada pelas autoras.

Além disso, categorias dimensão ambiental e ciência e tecnologia são as que mais se destacam. A CTS, dessa maneira, prevalece no Livro 2 (Figura 2), sendo que, em relação ao PNLD 2015/ Biologia, aparece mais que o dobro de vezes (Figuras 1 e 2). No L4, em CC, há a maior predominância das categorias, sendo que ciência e tecnologia e dimensão ambiental são as que se destacam (tabela 5), além da Botânica no cotidiano.

O ensino CTS também prevalece no conteúdo do livro 4 (Figura 2). A última categoria, formação de opiniões, pertencente a PNLD e CTS, apresentou um total de nove ocorrências, destacando-se em EX. Foram cinco casos em EX e um em CI no L2; no L3, esta apareceu uma vez em CC; em EX nos livros 4 e 5 houve um caso para cada livro; e não foi observada essa categoria (XVII) apenas no L1 (Tabelas 1 e 4).

Nas partes que focam na concepção de ensino CTS, há textos muito ricos e criativos, não obstante, como se tem dado preferência ao ensino da linguagem científica (majoritariamente) nos livros didáticos, seus efeitos acabam por refletir continuamente nas salas de aula, visto que os professores frequentemente utilizam o livro didático na construção de currículos escolares. Pode-se considerar que, por isso, não tenham sido encontrados excertos para serem classificados nas categorias conceitos em destaque e ética e valores da ciência e tecnologia no conteúdo de Botânica dos livros didáticos (tabelas 1 a 5). Afirma Santos (2008), quando trata da educação na concepção CTS na perspectiva humanística de Paulo Freire, que ela não pode ser limitada à 
busca por benefícios ou prejuízos trazidos pela tecnologia, mas que esteja envolvida realmente na vida humana, permeada de valores.

Tabela 5. Ocorrência das categorias no conteúdo do L4

\begin{tabular}{cclccccc}
\hline & \multicolumn{2}{c}{ Categorias } & CI & CP & CC & EX & Total \\
\hline PNLD 2015/ & I & A Botânica no cotidiano & 2 & 7 & 1 & 1 & 11 \\
Biologia & II & Respeito às formas de vida & 0 & 0 & 0 & 0 & 0 \\
& III & Conhecimentos populares & 0 & 0 & 0 & 0 & 0 \\
& IV & Caráter interdisciplinar & 0 & 0 & 3 & 1 & 4 \\
& V & Superação da visão a-histórica & 0 & 0 & 0 & 0 & 0 \\
& VI & História evolutiva & 0 & 7 & 0 & 0 & 7 \\
& VII & Espírito cooperativo & 0 & 0 & 0 & 0 & 0 \\
CTS & VIII & Espírito investigativo & 0 & 0 & 0 & 1 & 1 \\
& IX & Conceitos em destaque & 0 & 0 & 0 & 0 & 0 \\
& X & Ciência e tecnologia & 0 & 5 & 6 & 1 & 12 \\
& XI & Dimensão política & 0 & 0 & 6 & 0 & 6 \\
& XII & Dimensão social & 0 & 0 & 0 & 0 & 0 \\
& XIII & Dimensão ambiental & 0 & 1 & 9 & 1 & 11 \\
& XIV & Dimensão cultural & 0 & 0 & 0 & 0 & 0 \\
& XV & Ética e valores da ciência e tecnologia & 0 & 0 & 0 & 0 & 0 \\
& XVI & Pensamento crítico & 0 & 0 & 0 & 0 & 0 \\
PNLD e CTS & XVII & Formação de opiniões & 0 & 0 & 0 & 1 & 1 \\
& & & 2 & 20 & 25 & 6 & 53 \\
\hline
\end{tabular}

Fonte: Elaborada pelas autoras.

No entanto, mesmo sem essas ocorrências, o L2 destacou-se por haver apresentado a melhor diversidade de categorias (tabela 4) e maior quantidade de presenças no conteúdo em relação aos outros livros (tabela 4, figuras 1 e 2), demonstrando que o livro didático, amplamente usado em sala de aula, tenderia a melhorar se tivesse uma reformulação em sua escrita, que deveria ser voltada substancialmente ao ensino com enfoque CTS, visando à Alfabetização Científica. Esta aqui considerada, segundo Krasilchik e Marandino (2007, p. 30), “[...] como a capacidade de ler, compreender e expressar opiniões sobre ciência e tecnologia, mas também participar da cultura científica de maneira que cada cidadão, individual e coletivamente, considerar oportuno" e o ensino CTS como a melhor forma de, nos estudantes, alcançar a Alfabetização Científica (ACEVEDO DÍAZ, 2004; ACEVEDO DÍAZ; VÁZQUEZ ALONSO; MANASSERO MÁS, 2003).

Se a Alfabetização Científica do estudante é o que se almeja na Educação Básica, a linguagem que prioriza ensino de conceitos e descrições nos livros didáticos precisa deixar de ser tão destacada, o que poderia provocar uma mudança de postura de estudantes e de professores em sala de aula, pois não se visaria demasiadamente o aspecto de memorização de assuntos a 
serem tratados, principalmente com relação ao ensino de Botânica. Para Melo et al. (2012, p. 2), “[...] utilizar a alfabetização científica como referência no ensino de Botânica torna-se uma medida favorável, visto que esse processo permite a criação de novos significados diante de algo que se conhece, podendo dar sentidos aos fenômenos que são observados habitualmente".

Essa mudança tanto no livro didático quanto na postura de estudantes e docentes pode ser também relacionada ao ensino sob o enfoque CTS. O ensino CTS defende a adoção de abordagens pedagógicas diversificadas em sala de aula, envolvendo o desenvolvimento de pensamento crítico com relação às problemáticas relacionadas à ciência e suas interações com tecnologia e sociedade. Ou seja, preconiza que o professor abra mão do uso de estratégias arcaicas para conduzir o ensino de ciências, ressignificando a ideia de que é apenas o transmissor do conhecimento e o estudante o receptor como ocorre em aulas meramente expositivas (TEIXEIRA, 2003). Como afirmam Sá e Santin (2009, p. 159), quando se referem ao livro didático:

[...] é necessário que ele apresente uma proposta de trabalho que permita o desenvolvimento do raciocínio, da participação efetiva do aluno no seu aprendizado, que estimule a tomada de decisões, que tenha preocupação em resgatar os conhecimentos prévios, valorizando-os, [...] que se torne um instrumento de ensino dinâmico e instigante.

Isso não significa que o livro didático deva ser inutilizado, mas é importante que ele não se torne o estruturador do currículo, deixando de lado a importância de se considerar a realidade histórica, social e cultural na qual o estudante está inserido.

\section{Considerações finais}

Por esta análise do conteúdo de Botânica foi possível verificar que os volumes dos cinco livros didáticos examinados apresentavam, embora ainda de forma restrita, aspectos relacionados a um Ensino de Ciências embasado no enfoque CTS. Além disso, observou-se que o material tem condições de melhorar em relação ao ensino CTS e, consequentemente, às contribuições necessárias à formação da Alfabetização Científica nos estudantes da Educação Básica, uma vez que a escrita desses livros didáticos se fundamenta em documentos educacionais oficiais brasileiros. Estes, por sua vez, defendem a formação de estudantes para a ação cidadã, em que, por intermédio da atuação responsável e crítica, diante de questões que acometem seu meio social, possam ser capazes de efetivamente se envolver democraticamente na tomada de decisões de assuntos referentes à ciência e à tecnologia na sociedade em que vivem.

Reitera-se que esses livros didáticos, por si só, têm pouco dessa concepção de ensino, pois a parte maior deles (o conteúdo principal) é composta pela apresentação expressiva de conceitos, definições Botânicas e descrições de diferentes naturezas (morfológicas, fisiológicas, fenomenológicas, etc.), confirmando que esse aspecto precisa ainda ser explorado de forma reflexiva para alcançar superação, de modo que esse material possa colaborar para a formação integral e crítica do estudante.

O conteúdo principal é, sem dúvida, o corpo significativo dos livros didáticos disponíveis à aprendizagem dos alunos da Educação Básica. Isso indica que os docentes não precisam abrir 
mão dos livros didáticos, mas apenas não ficarem atrelados somente ao que esse instrumento pedagógico explora; precisam ficar atentos às finalidades do Ensino de Ciências para a formação da alfabetização científica dos estudantes, se for realmente isso que almejam.

Vale lembrar que o ensino da Botânica é muito mais que a memorização desenfreada de sistemas de classificação, termos e conceitos. Torna-se fundamental que os alunos compreendam e percebam, pelas relações CTS, que suas ações no ambiente interferem na sobrevivência de todos os seres vivos e, portanto, na deles próprios. A Botânica faz parte da vida do estudante: as plantas não servem só para a alimentação humana e de outros seres vivos (por exemplo), mas também são importantes ecologicamente ao sustento de toda a vida existente no planeta. Por isso, pode-se dizer que a Botânica oportuniza o desenvolvimento de temáticas mais amplas em sala de aula, pois estas fazem interconexões com o estudo das plantas. Biopirataria, organismos geneticamente modificados e monoculturas são exemplos de temáticas que podem ser relacionadas diretamente à Botânica e à preservação ambiental e, portanto, fazem parte do dia a dia dos estudantes. Assim, enquanto o Ensino da Botânica permanecer cerceado pela concepção tradicional de ensino, não fará sentido na aprendizagem do estudante nem contribuirá à alfabetização científica.

Dessa forma, este artigo aponta a necessidade de reformulação não só dos livros didáticos, mas dos currículos escolares atuais da Educação Básica. Os livros didáticos e os currículos deveriam, de fato, basear-se na concepção de ensino CTS, objetivando a Alfabetização Científica dos estudantes. Os professores, em sala de aula, precisariam desenvolver atividades pedagógicas diversificadas e interdisciplinares focadas também neste fim, sempre (re)avaliando sua prática docente, a fim de buscar um Ensino de Ciências mais qualificado. É necessário, além disso, que o Ensino de Ciências na Educação Básica realmente tenha propósitos transformadores, para que os estudantes, uma vez alfabetizados cientificamente, estejam preparados para contribuir na renovação e na ressignificação da Educação brasileira.

\section{Referências}

ACEVEDO DÍAZ, J. A. Reflexiones sobre las finalidades de la enseñanza de las ciencias: educación científica para la ciudadanía. Revista Eureka sobre Enseñanza y Divulgación de las Ciencias, Cádiz, v. 1, n. 1, p. 3-15, 2004. Disponível em: http://www.redalyc.org/ articulo.oa?id=92010102. Acesso em: 8 jan. 2018.

ACEVEDO DÍAZ, J. A.; VÁZQUEZ ALONSO, A.; MANASSERO MÁS, M. A. Papel de la educación CTS en una alfabetización científica y tecnológica para todas las personas. Revista Electrónica de Enseñanza de las Ciencias, Vigo, v. 2, n. 2, p. 80-111, 2003. Disponível em: http://reec.uvigo.es/volumenes/volumen2/REEC_2_2_1.pdf. Acesso em: 8 jan. 2018

AMABIS, J. M.; MARTHO, G. R. Biologia em contexto: a diversidade dos seres vivos. São Paulo: Moderna, 2013. 
Uma análise do conteúdo de Botânica sob o enfoque ...

AULER, D. Articulação entre pressupostos do educador Paulo Freire e do movimento CTS: novos caminhos para a educação em ciências. Contexto \& Educação, Ijuí, v. 22, n. 77, p. 167-188, 2007. Disponível em: https://www.revistas.unijui.edu.br/index.php/ contextoeducacao/article/view/1089/844. Acesso em: 8 jan. 2018.

AULER, D.; BAZZO, W. A. Reflexões para a implementação do movimento CTS no contexto educacional brasileiro. Ciência \& Educação, Bauru, v. 7, n. 1, p. 1-13, 2001. Disponível em: http://www.scielo.br/pdf/ciedu/v7n1/01.pdf. Acesso em: 8 jan. 2018.

BARDIN, L. Análise de conteúdo. São Paulo: Edições 70, 2011.

BISPO FILHO, D. O.; MACIEL, M. D.; SEPINI, R. P.; VÁZQUEZ ALONSO, A. Alfabetização científica sob o enfoque da ciência, tecnologia e sociedade: implicações para a formação inicial e continuada dos professores. Revista Electrónica de Enseñanza de las Ciencias, Vigo, v. 12, n. 2, p. 313-333, 2013. Disponível em: http:/ /reec.uvigo.es/ volumenes/volumen12/REEC_12_2_5_ex649.pdf. Acesso em: 8 jan. 2018.

BRASIL. Ministério da Educação. Diretrizes curriculares nacionais gerais da educação básica. Brasília, 2013.

BRASIL. Ministério da Educação. Guia de livros didáticos: PNLD 2015: ensino médio biologia. Brasília, 2014. Disponível em: https://www.fnde.gov.br/programas/programas-dolivro/pnld/guia-do-livro-didatico/item/5940-guia-pnld-2015. Acesso em: 15 fev. 2019.

BRÖCKELMANN, R. H. (ed.). Conexões com biologia. São Paulo: Moderna, 2013.

CAMPOS, F. R. G. Ciência, tecnologia e sociedade. Florianópolis: IFSC, 2010.

FIGUEIREDO, J. A.; COUTINHO, F. A.; AMARAL, F. C. O ensino de botânica em uma abordagem ciência, tecnologia e sociedade. In: SEMINÁRIO HISPANO BRASILEIRO CTS, 2., São Paulo, 2012. Anais [...]. Disponível em: http://revistapos.cruzeirodosul.edu.br/ index.php/rencima/article/viewFile/420/353. Acesso em: 8 jan. 2018.

GODOY, A. S. Pesquisa qualitativa: tipos fundamentais. Revista de Administração de Empresas, São Paulo, v. 35, n. 3, p. 20-29, 1995. DOI: https://doi.org/10.1590/S003475901995000300004.

KINDEL, E. A. I. Do aquecimento global às células tronco: sabendo ler e escrever a biologia do século XXI. In: PEREIRA, A. A. Ler e escrever: compromisso no ensino médio. Porto Alegre: Editora UFRGS, 2008. p. 91-102.

KRASILCHIK, M.; MARANDINO, M. Ensino de ciências e cidadania. 2. ed. São Paulo: Moderna, 2007.

LAJOLO, M. Livro didático: um (quase) manual de usuário. Em Aberto, Brasília, v. 16, n. 69, p. 3-9, 1996. Disponível em: http:/ / emaberto.inep.gov.br/index.php/emaberto/article/ view/2061/2030. Acesso em: 18 fev. 2019.

MELO, E. A.; ABREU, F. F.; ANDRADE, A. B.; ARAÚJO, M. I. O. A aprendizagem de botânica no ensino fundamental: dificuldades e desafios. Scientia Plena, Aracaju, v. 8, n. 10, p. 1-8, 2012. Disponível em: https://www.scientiaplena.org.br/sp/article/view/492. Acesso em: 8 jan. 2018. 
MENDONÇA, V. L. Biologia: os seres vivos: ensino médio. 2. ed. São Paulo: AJS, 2013. v. 2. MENEZES, L. C.; SOUZA, V. C.; NICOMEDES, M. P.; SILVA, N. A; QUIRINO, M. R.; OLIVEIRA, A. G.; ANDRADE, R. R. D.; SANTOS, B. A. C. Iniciativas para o aprendizado de botânica no ensino médio. In: ENCONTRO DE INICIAÇÃO À DOCÊNCIA, 11., João Pessoa, 2008. Anais [...]. Disponível em: http://www.prac.ufpb.br/anais/xenex_xienid/ xi_enid/prolicen/ANAIS/Area4/4CFTDCBSPLIC03.pdf. Acesso em: 12 jan. 2017.

OSORIO, T. C. (ed.). Ser protagonista: biologia, 2: ensino médio. 2. ed. São Paulo: Edições SM, 2013.

ROCKENBACH, M. E.; OLIVEIRA, J. H. F.; PESAMOSCA, A. M.; CASTRO, P. E. E.; MACIAS, L. Não se gosta do que não se conhece?: a visão de alunos sobre a botânica. In: CONGRESSO DE INICIAÇÃO CIENTÍFICA, 21., Pelotas, 2012. Pelotas: Universidade Federal de Pelotas, 2012. Anais [...]. Disponível em: http://www2.ufpel.edu.br/cic/2012/ anais/pdf/CH/CH_01069.pdf. Acesso em: 28 fev. 2018.

SÁ, M. B. Z.; SANTIN, O. Relações entre ciência, tecnologia e sociedade em livros didáticos de química. Acta Scientiarum. Human and Social Sciences, Maringá, v. 31, n. 2, p. 159166, 2009. Disponível em: http://eduem.uem.br/ojs/index.php/ActaSciHumanSocSci/ article/download/461/461. Acesso em: 28 fev. 2018.

SANTOS, W. L. P. Educação científica humanística em uma perspectiva freireana: resgatando a função do ensino CTS. Alexandria: revista educação em ciência e tecnologia, Florianópolis, v. 1, n. 1, p. 109-131, 2008. Disponível em: https://periodicos.ufsc.br/index.php/alexandria/ article/view/37426/28747. Acesso em: 28 fev. 2018.

SILVA, C.; SASSON, S.; CALDINI, N. Biologia 2. 11. ed. São Paulo: Saraiva, 2013.

SOUZA, C. L. P.; KINDEL, E. A. I. Compartilhando ações e práticas significativas para o ensino de botânica na educação básica. Experiências em Ensino de Ciências, Porto Alegre, v. 9, n. 3, p. 44-58, 2014. Disponível em: http://if.ufmt.br/eenci/artigos/Artigo_ ID253/v9_n3_a2014.pdf. Acesso em: 28 fev. 2018.

TEIXEIRA, P. M. M. A educação científica sob a perspectiva pedagógica histórico-crítica e do movimento C.T.S. no ensino de ciências. Ciência \& Educação, Bauru, v. 9, n. 2, p. 177-190, 2003. Disponível em: <http://www.scielo.br/pdf/ciedu/v9n2/03.pdf>. Acesso em: 28 fev. 2018.

Artigo recebido em 07/05/2018. Aceito em 25/08/2018.

Contato: UFRGS, Departamento de Bioquímica, Rua Ramiro

Barcelos, 2600, Porto Alegre RS 90035003, Brazil. 